\section{NOTICE OF ERRATA}

In the print version of the article Tenney HR, Boyle KL, DeBord A. Influence of hamstring and abdominal muscle activation on a positive Ober's test in people with lumbopelvic pain. Physiother Can. 2013;65(1):4-11, the instructions accompanying Figure 1 contain an error. Steps 1-4 and 7-13 in the print version are correct; steps 5 and 6 should be omitted. The author regrets this error. An updated version of the article that includes the correct instructions is available online at http://dx.doi.org/ 10.3138/ptc.2011-33.

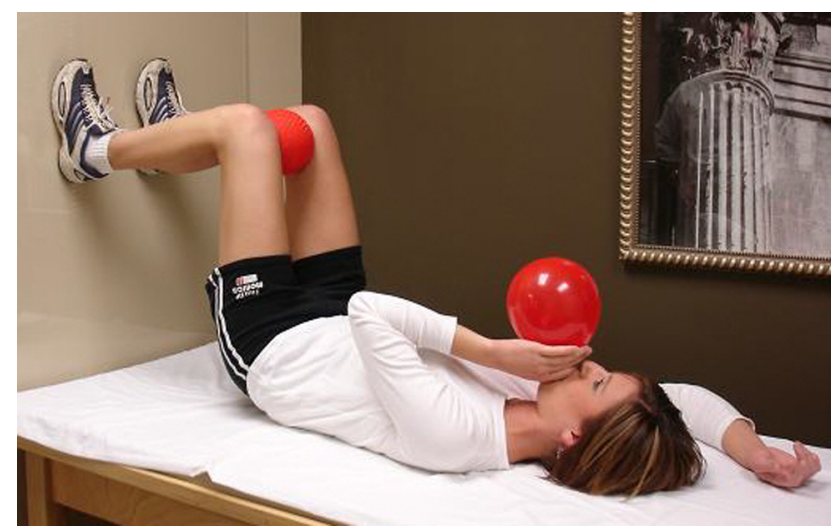

Figure $1 \quad 90 / 90$ hip lift with balloon.
Instructions:

1. Lie on your back with your feet flat on a wall and your knees and hips bent at a $90^{\circ}$ angle.

2. Place a 4-6" ball between your knees.

3. Place your right arm above your head and a balloon in your left hand.

4. Inhale through your nose and as you exhale through your mouth perform a pelvic tilt so that your tailbone is raised slightly off the mat. Keep your low back flat on the mat. Do not press your feet flat into the wall; instead, dig down with your heels.

5. Now inhale through your nose and slowly blow out into the balloon.

6. Pause 3 seconds with your tongue on the roof of your mouth to prevent airflow out of the balloon.

7. Without pinching the neck of the balloon, and keeping your tongue on the roof of your mouth, inhale again through your nose.

8. Slowly blow out as you stabilize the balloon with your hand.

9. Do not strain your neck or cheeks as you blow.

10. After the fourth breath in, pinch the balloon neck and remove it from your mouth. Let the air out of the balloon.

11. Relax and repeat the sequence 4 more times.

(C) Postural Restoration Institute 2009; used with permission 